\title{
A percepção dos trabalhadores de saúde mental sobre a atuação do redutor de danos
}

\section{Diego Fernandes Leal ${ }^{1}$ \\ (D) https://orcid.org/0000-0002-1954-066x \\ Vanessa Alvez Mora da Silva ${ }^{1,2}$ \\ (D) https://orcid.org/0000-0003-0235-7663 \\ Luana Ribeiro Borges ${ }^{1}$ \\ (D) https://orcid.org/0000-0002-9772-5969 \\ Sandra Beatris Diniz Ebling ${ }^{1,3}$ \\ (D) https://orcid.org/0000-0002-0876-5206 \\ Aline Ost dos Santos ${ }^{4}$ \\ (DiD https://orcid.org/0000-0002-1849-9933}

\footnotetext{
${ }^{1}$ Universidade Federal do Pampa, Uruguaiana, RS, Brasil.

2 Universidade Federal do Rio Grande do Sul, Porto Alegre, RS, Brasil.

${ }^{3}$ Universidade Federal do Rio Grande, Carreiros, RS, Brasil.

${ }^{4}$ Prefeitura Municipal de Uruguaiana, Secretaria de Saúde Municipal, Uruguaiana, RS, Brasil.
}

Objetivo: conhecer a percepção dos trabalhadores sobre a atuação do redutor de danos em um Centro de Atenção Psicossocial de Álcool e outras drogas (CAPSad), assim colaborando com a problematização e transformação da realidade do cuidado aos usuários de álcool e outras drogas.

Método: trata-se de uma pesquisa qualitativa e exploratória, de caráter descritivo, realizada com profissionais de um CAPSad da cidade de Sant'Ana do Livramento por meio da técnica de Grupo Focal Narrativo (GFN). Para realizar a análise dos dados, o conteúdo foi transformado em narrativa de grupo.

Resultados: apontou-se a discussão frente à percepção da figura do redutor de danos e sua inter-relação no cotidiano da clínica em saúde mental, apresentando potências e desafios. Conclusão: evidencia-se a importância do papel que a redução de danos ocupa no âmbito da Reforma Psiquiátrica Brasileira. A figura do redutor de danos no serviço é de que este profissional tem como capacidade a criação de vínculos, realização de um acolhimento efetivo e que pode auxiliar na desconstrução do estigma que o usuário de substâncias sofre perante a sociedade, sendo uma ferramenta potente para a construção e transmutação na vida das pessoas.

Descritores: Saúde Mental; Serviços de Saúde Mental; Redução do Dano; Assistência à Saúde; Integralidade em Saúde.

\section{Como citar este artigo}

Leal DF, Silva VAM, Borges LR, Ebling SBD, Santos AO. The perception of mental health workers about the performance of the damage reducer. SMAD, Rev Eletrônica Saúde Mental Álcool Drog. 2021 jan.- mar.;17(1):66-74. doi: https://dx.doi.org/10.11606/issn.1806-6976.smad.2021.165211 


\section{The perception of mental health workers about the performance of the damage reducer}

Objective: to know the workers' perception about the performance of the damage reducer in a Psychosocial Care Center for Alcohol and other drugs (PSCCad), thus collaborating with the problematization and transformation of the reality of the care for users of alcohol and other drugs. Method: this is a qualitative and exploratory research, of a descriptive nature, carried out with professionals from a PSCCad in the city of Sant'Ana do Livramento using the Narrative Focus Group (NFG) technique. In order to perform the data analysis, the content was transformed into group narrative. Results: the discussion was pointed out in the face of the perception of the figure of the damage reducer and its interrelation in the daily routine of the mental health clinic, presenting strengths and challenges. Conclusion: it is evident the importance of the role that damage reduction plays in the scope of the Brazilian Psychiatric Reform. The figure of the damage reducer in the service is that this professional has the capacity to create bonds, perform an effective welcoming and that can assist in deconstructing the stigma that the substance user suffers in society, being a powerful tool for construction and transmutation in people's lives.

Descriptors: Mental Health; Mental Health Services; Harm Reduction; Delivery of Health Care; Integrality in Health.

\section{La percepción de los trabajadores de salud mental sobre la actuación de reductor de daños}

Objetivo: comprender la percepción de los trabajadores sobre el papel de la reducción de daños en un Centro de Atención Psicosocial para el Alcohol y otras Drogas (CAPSad), colaborando con la problematización y transformación de la realidad de la atención a los consumidores de alcohol. y otras drogas. Método: investigación descriptiva, cualitativa y exploratoria, realizada con profesionales de un CAPSad en la ciudad de Sant'Ana do Livramento, utilizando la técnica del Narrative Focus Group (GFN). Para realizar análisis de datos, el contenido se transformó en una narración grupal. Resultados: la discusión se señaló frente a la percepción de la figura del reductor de daños y su interrelación en la rutina diaria de la clínica de salud mental, presentando fortalezas y desafíos. Conclusión: la importancia del papel que juega la reducción de daños en el contexto de la Reforma Psiquiátrica brasileña es evidente. La figura del reductor de daños en el servicio es que este profesional tiene la capacidad de crear vínculos, realizar una bienvenida efectiva y que puede ayudar a deconstruir el estigma que sufre el usuario de sustancias en la sociedad, siendo una herramienta poderosa para la construcción y transmutación en la vida de las personas.

Descriptores: Salud Mental; Servicios de Salud Mental; Reducción del Daños; Prestación de Atención de Salud, Integralidad en Salud. 


\section{Introdução}

A proposta de uma política pública de saúde para os usuários de álcool e outras drogas deu-se no Brasil no ano de 2003, influenciada pela experiência da reforma psiquiátrica, indicando para uma constituição de rede de serviços abertos e territorializados e pelo Programa de IST/ Aids a partir das estratégias de redução de danos $(R D)^{(1)}$.

A origem do modelo de RD deu-se no Reino Unido em 1926 e preconizava que os usuários em situação de dependência de opioides poderiam receber estas drogas sob a prescrição de um médico(2).

Em 1984, na Holanda, as estratégias de RD, propostas pelos próprios usuários de drogas injetáveis, foram utilizadas no controle das epidemias de hepatites B e C e da Aids(3).

Após longos anos, acontece a primeira experiência brasileira de RD, em 1989, na cidade de Santos, São Paulo, consistindo principalmente em ações de troca de seringas para usuários de drogas injetáveis. Foi uma experiência inovadora e transgressora, pois profissionais envolvidos com essa experiência tiveram de enfrentar inquéritos policiais e ações judiciais e, embora associada principalmente ao controle e à prevenção de Infecções Sexualmente Transmissíveis (ISTs)/Síndrome de Imunodeficiência Adquirida (Aids), também começou a desencadear uma nova dinâmica de propostas de cuidado de si fundamentada no protagonismo de minorias marginalizadas, no estabelecimento de trocas afetivas e na construção de vínculos cooperativos ${ }^{(4)}$.

No Rio Grande do Sul (RS), a RD iniciou nos anos 90 como uma estratégia de prevenção à Aids e apenas depois aproximou-se com os serviços de saúde mental. Entre as primeiras experiências de Programas de Redução de Danos do Estado, destaca-se o município de Sant'Ana do Livramento que, apesar de ter iniciado como estratégia preventiva no campo da Política de IST/Aids, já mostrava potência como tecnologia de cuidado em saúde mental, atuando em um território de fronteira e vulnerabilidade ${ }^{(5)}$. Atualmente, o município é uma referência na prática e realiza um trabalho importante na área de RD, originando o interesse no local de estudo.

Dessa forma, a RD conceitua-se, de modo geral, como qualquer ação que vise a minimizar os riscos e danos causados pelo uso de álcool e outras drogas à saúde de um indivíduo. Porém, está voltada não apenas para a promoção da saúde, mas também à valorização da cidadania e à garantia dos direitos humanos(6).

Considera-se a RD uma abordagem horizontal na relação do cuidado, uma vez que, na relação entre profissional e usuário de drogas, não existe a premissa de superioridade. Assim, o próprio usuário deve tomar a iniciativa na estruturação de estratégias para cuidar de sua saúde, junto com instâncias políticas de gestão em saúde no desenvolvimento de programas, e, como resultado, promove-se o acesso a serviços de baixa exigência e de baixo custo(7).

Com o objetivo de promover saúde entre populações com comportamentos e práticas de risco, a RD para usuários de álcool e outras drogas tem uma linha de atuação de respeito aos direitos do cidadão. Parte-se da premissa de que uma parte das pessoas que consomem algum tipo de droga, seja ela lícita ou ilícita, não consegue ou não quer parar de usar, todavia, não perde, por isso, o direito ao cuidado à saúde ou qualquer outro(8).

As estratégias de RD são construídas pela figura do redutor de danos, o qual se caracteriza por ser um profissional que desempenha atividades que visam a garantir a atenção e a defesa às pessoas em situação de risco pessoal e social, assim como aproximar as equipes dos valores, modos de vida e cultura das pessoas em situação de rua, trabalhando junto a usuários de álcool, crack e outras drogas, realizando atividades educativas e culturais, dispensação de insumos de proteção à saúde, facilitando e mediando o processo de encaminhamento dos usuários para a Rede de Atenção à Saúde e intersetorial ${ }^{(9)}$.

O profissional redutor de danos é aquele que estabelece contato direto com a comunidade, opera em um sentido de "busca ativa" dos usuários de drogas, mapeando suas redes sociais, locais de uso, práticas de risco, sempre amparado na formação de um vínculo com o usuário(10).

O estudo justifica-se pela importância da RD inserida como uma estratégia para minimizar os riscos à saúde das pessoas usuárias dos serviços de saúde mental, possuindo, como princípio fundamental, o respeito à liberdade de escolha e o acesso aos serviços de saúde. Além disso, outra motivação para a realização desta investigação refere-se à lacuna identificada na literatura sobre a importância real do redutor de danos. A maior parte do conhecimento produzido sobre essa temática advém de pesquisas que abordam a RD como uma possibilidade de diminuir os riscos relacionados à exposição decorrente do uso de drogas, entretanto, a RD não se resume a isso e não visa, necessariamente, a fazer com que o sujeito deixe de usar drogas, mas sim possibilitar uma aproximação com o usuário de modo humanizado, respeitando os desejos da pessoa e acolhendo-a, independentemente de ela seguir as recomendações do tratamento, sem impor obrigações ${ }^{(11)}$.

Formulou-se, tendo em vista a relevância da participação do redutor de danos nas ações de cuidado realizadas aos usuários de álcool e outras drogas e considerando que, na atualidade, a atenção à saúde dos usuários de substâncias psicoativas está passando por um processo de arruinação, norteada pelo Decreto $n .^{\circ}$ 9761, de 2019, que institui uma nova Política Nacional sobre Drogas (PNAD), priorizando ações de promoção e manutenção da abstinência(12), a seguinte questão norteadora: "Qual a percepção da equipe de trabalhadores 
sobre a atuação do redutor de danos em um CAPSad da região Sul do Brasil?". A partir desse questionamento, objetivou-se conhecer a percepção da equipe de trabalhadores sobre a atuação do redutor de danos em um CAPSad da região Sul do Brasil.

\section{Método}

Trata-se de uma pesquisa qualitativa e exploratória, de caráter descritivo. Configura-se como qualitativa, pois se ocupa de um conjunto de fenômenos humanos que contemplam o universo dos significados, dos motivos, das aspirações, dos valores e das atitudes, constituindo-se, dessa forma, como parte da realidade social(13). A pesquisa exploratória começa com um fenômeno de interesse, provendo conhecimentos e detalhes dos diferentes modos que este se apresenta, ao passo que os estudos descritivos abrangem a observação, a explicação e a classificação das dimensões, variações e a relevância do problema estudado(14).

O cenário deste estudo foi o Centro de Atenção Psicossocial de Álcool e outras drogas (CAPSad) da cidade de Sant'Ana do Livramento (RS), pertencente à $10^{a}$ Coordenadoria Regional da Saúde do Rio Grande do Sul (10a CRS/RS). A seleção dos participantes deu-se de maneira intencional para garantir homogeneidade do grupo e utilizaram-se os seguintes critérios de inclusão: profissionais de saúde que atuassem no CAPSad há, pelo menos, seis meses, não havendo interrompido o exercício funcional durante a coleta de dados da pesquisa; aceitar participar do estudo. Foram excluídos desta pesquisa os profissionais de saúde que estavam afastados do exercício laboral por licença médica, férias ou qualquer outro motivo e/ou recusaram-se a participar do estudo.

A coleta das informações ocorreu no mês de setembro do ano de 2018 por meio da técnica de Grupo Focal Narrativo (GFN), sendo audiogravada e transcrita na íntegra. O grupo focal foi realizado com sete profissionais do serviço. Para realizar a análise dos dados, o conteúdo foi transformado em narrativa de grupo, validada por dois pesquisadores. Optou-se por esse tipo de método, pois permite um debate, ao passo que os participantes são estimulados pelos moderadores a explorar as percepções coletivas a respeito do objeto, visto que os entendimentos individuais são uma parcela do contexto a ser analisado(15).

O grupo focal foi realizado nas dependências do CAPSad de Sant'Ana do Livramento e teve duração de aproximadamente duas horas, sendo mediado por um moderador e um apoiador guiados por fragmentos de casos clínicos fictícios (vinhetas), na composição de um roteiro de investigação distinto para o segmento de trabalhadores, utilizando uma história fictícia em que os participantes do estudo são os profissionais de referência e, assim, promovendo uma discussão acerca do cuidado em um CAPSad.
Os dados foram analisados sob a luz da hermenêutica crítica em um compromisso com a verdade, entendendo que a realidade não é, mas se torna à medida que é construída por pessoas em um dado tempo histórico, em um processo democrático no qual investigador e investigado percebem-se entrelaçados ${ }^{(16)}$. Esse método consiste em abrir-se para o encontro, possibilitando ao outro ter direito, e não se pretendendo ter a última palavra. Trata-se de uma "verdade prática", um processo contínuo que permanece em ressignificação ilimitada enquanto se mantiver aberta a possibilidade de interação(17). O que se defende, neste método, é a manutenção de uma postura interrogativa, a qual se sustenta na possibilidade de corrigirem-se "conceitos prévios em um constante projetar de opiniões", na qual a verdade se "re/des/constrói a cada diálogo", em um vai e vem compreensivo/interpretativo(18).

Informa-se que este estudo é um recorte da pesquisa intitulada "A clínica no contexto do uso de SPA: a percepção de usuários, trabalhadores e gestores acerca do cuidado em saúde mental", sendo registrado no Sistema de Informações de Projetos de Pesquisa, Ensino e Extensão (SIPPEE) sob o número de cadastro 20170526125153 e aprovado pelo Comitê de Ética em Pesquisa (CEP) da Universidade Federal do Pampa (UNIPAMPA), por meio do Parecer no 2281711, em 18 de setembro de 2017.

Ressalta-se que todos os participantes assinaram o Termo de Consentimento Livre e Esclarecido (TCLE) de acordo com o determinado pela Resolução no 466/2012 referente à pesquisa envolvendo seres humanos.

\section{Resultados}

Dentre os participantes do estudo, estavam as seguintes formações profissionais: técnicos em Enfermagem; terapeuta ocupacional; redutor de danos e enfermeiro.

A percepção da figura do redutor de danos e sua inter-relação no cotidiano da clínica em saúde mental: apresentando potenciais e desafios.

A narrativa dos trabalhadores descreve a mudança do trabalho dos redutores de danos, trazendo questões referentes ao contexto histórico da RD em que vai progressivamente deixando de ser uma medida exclusivamente de prevenção às ISTs e tem o seu campo de intervenção ampliado devido à participação direta das pessoas que fazem uso de drogas nas práticas de gestão e atenção, o que pode ser percebido na narrativa abaixo.

Quando começamos a fazer redução de danos, há muito tempo atrás, era tipo trocar seringa, dar camisinha, encaminhamento quando possível; hoje em dia, a redução de danos é muito mais que isso, ela atua dentro de CAPS, de escolas, de presídios, casas noturnas, dentro da prática de esportes. A redução de danos tornou-se um diferencial na saúde pública, nos CAPS e nos serviços especializados. (Narrativa do Grupo Focal) 
Os participantes relataram sobre a importância da RD no cotidiano do trabalho e alguns profissionais com experiência no programa descreveram que estão em constante aprendizado e que a redução mudou a vida de muitos usuários e profissionais que, posteriormente, se tornaram redutores de danos, mas já foram usuários outrora. O coletivo acredita que o redutor de danos tem uma formação diferente da de outros profissionais dentro de um serviço de álcool e drogas, baseada em um cuidado constituído de um conjunto de estratégias singulares e coletivas, o que pode ser visualizado na narrativa que se segue.

Estamos sempre aprendendo com a redução de danos; ela transformou vidas de muitos redutores de danos; acreditamos que ela pode fazer a diferença; é fato que nem todos os usuários vão poder virar trabalhadores de saúde, mas a redução de danos tem essa capacidade de mudança. O redutor de danos não é melhor nem pior que ninguém, ele tem formação diferente, pois é uma formação realizada na prática, no cuidado. (Narrativa do Grupo Focal)

Realizamos redução de danos todos os dias no serviço; no momento que a gente está tentando promover saúde para alguém, a gente está reduzindo o dano, um dano de saúde, social, físico, de uso de drogas. A redução de danos também é pensada na questão da conscientização, às vezes, numa abordagem de uma família, a gente está reduzindo os danos, só o fato do profissional redutor de danos estar aqui, está reduzindo um dano. (Narrativa do Grupo Focal)

Nesta perspectiva, os discursos salientaram o respeito ao usuário e a não imposição da abstinência como pressupostos da RD na produção do cuidado dispensado, mesmo ele fazendo uso de determinada substância psicoativa.

Pensamos que a abstinência pode ser algo alcançado, mas não deve ser uma condição para o acesso, é uma decisão que pode e deve vir do outro, não nossa. Há pessoas que não vão conseguir lidar com essa situação, a abstinência é de cada um e é uma coisa que pode ser alcançada, mas, para cada caso, respeitando a liberdade de escolha daqueles que não querem e os que não conseguem. (Narrativa do Grupo Focal)

O grupo relatou sobre o respeito ao usuário e a utilização de tecnologias leves, como o acolhimento e a disponibilidade para escuta, para que se crie um vínculo com o usuário, o que, muitas vezes, é o que faz com que ele retorne ao CAPS logo após uma recaída.

Quando realizamos o acolhimento, busca-se a criação de um vínculo com o usuário, para ele saber que tem uma pessoa, uma instituição que ele possa confiar; em nossa experiência, já ocorreram casos de usuários que voltaram ao uso, fazendo as mesmas coisas antes do ingresso ao CAPS, mas ele sabia que existia um vínculo de proteção, de confiança, de entender a situação dele e acabou voltando, às vezes, só para dar um tempo, refletir, e é o tempo para começar a fazer uma redução, fazer pensar em algum projeto para tratar com ele. Por isso, é necessário dispor de uma boa conversa para saber a história da vida dele; assim, o mesmo vai te dizer muito mais de que um questionário. (Narrativa do Grupo Focal)

Para os participantes deste estudo, a presença do profissional redutor de danos é uma estratégia que contribui para que o usuário aceite melhor o tratamento, assim como os relacionamentos afetivos no serviço de saúde.

Muitas vezes, os usuários têm dificuldades em relação à adaptação, onde referem que não gostam de fulano ou ciclano e, neste momento, o apoio dos redutores de danos do serviço é importante, pois nos auxiliam, conversando com quem tem mais vínculo, motivando-o a participar das atividades, assim ocorrendo uma melhor adesão. Não obrigamos os usuários a participarem das atividades, concordamos que se ele está aqui no serviço, pelo menos, ele está reduzindo os danos, não está fazendo uso. (Narrativa do Grupo Focal)

Neste sentido, os usuários não são obrigados a aderir a um plano terapêutico, eles são motivados a participar das atividades e apoiados para que ocorra uma melhor adesão ao tratamento.

Em relação aos desafios enfrentados pelos profissionais na prática diária, salienta-se que os CAPS são serviços com grande potencial para a transformação do modelo de atenção em saúde mental e trazem para si o desafio cotidiano de promover mudanças na vida das pessoas em sofrimento psíquico em consequência do uso de substâncias psicoativas. Assim, a palavra terapêutica norteia a prática dos profissionais e realiza-se ao produzir sentido e diferenças na vida das pessoas. Essa concepção sobre o que é terapêutico fica evidente na narrativa dos profissionais, que expressam os desafios encontrados para a realização de cuidados.

Uma da dificuldade que temos na nossa prática diária é sustentar o Plano Terapêutico Singular (PTS); inventamos, reinventamos, chamamos todos para participar, para ajudar a construir. As oficinas são abertas e, muitas vezes, há pouca adesão, poucos ficam, sempre tem quem, não quer participar e, com isso, muitas vezes, a gente se sente frustrado, então, ocorre essa dificuldade de sustentar um plano terapêutico singular, que não deixe ninguém excluído. (Narrativa do Grupo Focal)

Enfrentamos dificuldades com o fato de o usuário dormir no serviço, pois, no momento que passa toda uma noite de uso, caminhando, o organismo precisa de horas de descanso, sono, alimentação, de cuidado para ele recuperar. Porém, nos perguntamos em o que nós, como profissionais, estamos acrescentando para eles. De manhã, existe uma regra no serviço que não pode dormir, mas 
a gente percebe que, às vezes, é importante a pessoa dormir, ela precisa daquela hora de sono, tendo em vista que o mesmo segue no uso diário. (Narrativa do Grupo Focal)

Além disso, são enfrentadas dificuldades em relação ao julgamento moral que alguns profissionais apresentam na tentativa de cuidar do usuário, que são revogadas a partir da preocupação do grupo focal com o cuidado integral ao usuário, conduzindo a condições de reinventar o trabalho, repensar processos e desenhar novas alternativas para o cuidado.

\section{Discussão}

O modo de cuidado proposto pela estratégia RD transformou-se com a evolução das políticas públicas sobre uso de drogas, o que fez com que a equipe de trabalhadores em saúde mental tradicional incorporasse o cuidado e a visão do redutor de danos no dia a dia do CAPS.

Esta transformação atinge a maneira de entender o consumo de SPAs, sendo a RD o primeiro movimento a criticar o modelo internacional de proibição às drogas, iniciando uma caminhada, nos anos 80 , com a criação dos programas de troca de seringas para conter a disseminação de hepatites e, posteriormente, HIV e outras doenças infectocontagiosas entre usuários de drogas injetáveis. Dessa forma, foi a epidemia da Aids que conduziu as medidas de prevenção ao uso de drogas, contudo, a configuração atual da estratégia de RD não corresponde fidedignamente à dos anos 80(19).

No município que sediou esta pesquisa, a história da RD também transitou entre as ISTs e a Saúde Mental, ressaltando um novo modo de atuar, tratado como potencialidade pelos profissionais do CAPS, pois, com a inserção dos redutores de danos no serviço de saúde mental, estes recriam-se a cada encontro e desafiam-se a criar novas formas de cuidar dos usuários de SPA.

A RD pode ser percebida como transformadora do modelo biomédico, ainda que este seja hegemônico nas práticas de saúde, pois não se trata de um conceito único, mas se refere, basicamente, às políticas e programas de intervenção cujo objetivo é minimizar riscos, sem necessariamente diminuir o consumo individual de substâncias psicoativas. Alguns autores atestam que esta se alicerça em três importantes aspectos: a não exigibilidade da abstinência; o direito de participação política das pessoas que usam drogas; o trabalho de campo territorializado e em horários estratégicos. Assim, as atividades dentro dessa proposta constroem-se como medidas de saúde pública que têm o objetivo de minimizar os efeitos adversos do uso de drogas por meio da construção de vínculos e atos de cuidado e autocuidado, respeitando a autonomia e a liberdade de escolha das pessoas ${ }^{(20)}$

Portanto, ter um profissional redutor de danos ocupando o espaço na saúde mental permite enxergar o usuário de drogas de uma forma mais abrangente, com diversas necessidades e potencialidades, não se limitando somente à prevenção de ISTs e abstinência como meta final de tratamento, conforme destacado nos resultados. Dessa forma, a estratégia de RD busca diferenciar repercussões na saúde dos indivíduos e suas relações comunitárias, bem como custos econômicos e impactos sociais relacionados às políticas sobre drogas ${ }^{(21)}$. Aceitou-se, progressivamente, corroborando a legislação brasileira sobre drogas, esta estratégia como válida aos cuidados dos usuários de álcool e outras drogas, e um marco considerado de grande importância foi a aprovação da Lei Federal $n^{\circ}$ 10.216, de 2001, que legitimou a Reforma Psiquiátrica Brasileira(19).

Diante disso, os profissionais redutores de danos devem adotar uma postura ética, respeitosa e acolhedora, facilitando a vinculação dos usuários aos serviços de saúde, diminuindo, assim, estigmas e preconceitos sofridos por esta população, gerando um atendimento mais humanizado.

Pode-se dizer que parte das dificuldades e angústias levantadas pela equipe durante o grupo focal relacionava-se ao acolhimento e a como lidar com casos em que o usuário chega para o serviço sob o efeito de drogas ou pelo fato de dormir durante as atividades, sendo que, apesar das dificuldades, ele é acolhido. Contudo, prevalece a lógica de que ele desrespeita uma regra institucional rigorosa e que não se adequa à rotina de tratamento.

Embora, neste local, haja um movimento a favor das transformações no cuidado aos usuários de drogas, em alguns momentos, ele é permeado pela rigidez, o que aparenta sustentar uma lógica de cuidado excludente, muitas vezes travestida de um discurso cientificista que tenta legitimar a abstinência como terapêutica exclusiva a ser adotada nesses locais.

Em situações de crise, o acolhimento necessita despertar, no trabalhador, uma postura para dar suporte, valorizar o sujeito como ser humano e não apenas como doente, respeitando seu tempo, sua individualidade e singularidade. A crise, neste caso, o uso abusivo de substâncias psicoativas, não se constitui em uma situação ruim, que precisa ser bloqueada e controlada com maior rapidez, mas sim precisa ser encarada com humanização e sensibilidade por parte da equipe, visando aos sentimentos dos usuários ${ }^{(22)}$.

Outra questão relevante é a ambivalência durante a atuação da equipe, ora acolhedora ora moralista, e aqui cabe salientar que o papel do CAPSad não é decidir pelo usuário, mas sim construir um projeto terapêutico junto com ele e sua família, levando em consideração questões que vão além de sua saúde.

Salienta-se que a função dos trabalhadores do serviço especializado e do redutor de danos deve se apoiar 
na promoção do exercício da cidadania do usuário, o que significa o reconhecimento, em primeiro lugar, da condição de cidadão portador de direitos, antes da condição de usuário de drogas na sociedade.

Diante do exposto e a partir da análise das falas dos profissionais, pôde-se constatar que os trabalhadores reconhecem os efeitos que essas substâncias psicoativas provocam no organismo e a importância da realização de um acolhimento de forma a estabelecer vínculos e a garantir a continuidade do tratamento. No entanto, algumas normas e rotinas de funcionamento do serviço CAPSad mencionadas na narrativa parecem sustentar-se em uma lógica excludente em relação ao usuário de drogas, muitas vezes, remodelado de um discurso cientificista, que tenta legitimar a abstinência como terapêutica exclusiva a ser adotada nessa clínica. Quando a equipe consegue dialogar sobre a complexidade que o consumo abusivo de substâncias psicoativas proporciona, faz refletir sobre as lacunas assistenciais existentes na atenção à saúde tanto dos usuários quanto de suas famílias(23).

Ao suspender a ideia da abstinência como objetivo exclusivo do tratamento, a RD suspende igualmente a homogeneização que ela implica e ressalta a importância do reconhecimento da singularidade de cada caso, das múltiplas possibilidades de vinculação com as drogas e do respeito às diferenças e escolhas individuais. No mesmo sentido, também é proposta a suspensão dos valores morais e dos posicionamentos prescritivos e introduzida a aceitação de que algumas pessoas não podem, não querem ou não conseguem interromper o uso de drogas, sem que isso represente a impossibilidade de outros ganhos e processos terapêuticos ${ }^{(20,24)}$.

Por meio dos fragmentos narrativos, pode-se também compreender a importância do vínculo dentro de um serviço de atenção psicossocial, onde se permite traçar linhas que compõem a rede afetiva o indivíduo, seus gostos e desgostos, de maneira que se tem, com isso, a matéria com a qual se pode construir uma concepção de sua singularidade e montar, junto com o mesmo, um Projeto Terapêutico Singular (PTS).

Os agentes redutores de danos são os principais responsáveis pela aproximação entre o usuário e os serviços de saúde por meio dos encaminhamentos efetuados em campo. Com isso, muitas vezes, estabelecem o primeiro vínculo do usuário de drogas com um profissional da saúde(25).

Sabe-se que a equipe de atuação no CAPS deve ser multiprofissional e estar voltada a facilitar a interação paciente/família/comunidade por meio de atividades desenvolvidas no serviço(26). Assim, o PTS e a redução de danos inseridos nos CAPS ajudam a operacionalizar a perspectiva de uma clínica ampliada, que possibilita a ocorrência de dimensões subjetivas e a reconfiguração dos territórios existenciais, tanto dos trabalhadores em saúde quanto daqueles que eles cuidam. A dimensão processual desse modo de produção do cuidado apoia e projeta a construção da integralidade em saúde na perspectiva de autonomia e emancipação dos sujeitos e coletivos.

As ações de RD podem ser realizadas por qualquer profissional que deseje trabalhar com esta estratégia e tomam, como fundamental, a valorização do desejo e das possibilidades dos sujeitos para os quais estão orientadas as ações, baseadas no diálogo e na negociação com os sujeitos. Essa centralidade no sujeito, considerando seus desejos e possibilidades, caracteriza uma abordagem em saúde menos normatizadora e prescritiva, pois se evita ditar ou impor quais seriam as escolhas e atitudes adequadas ou não a serem adotadas. Assim, atuar em uma perspectiva de redução de danos pressupõe a utilização de tecnologias relacionais centradas no acolhimento empático, no vínculo e na confiança como dispositivos favorecedores da adesão da pessoa nas atividades de seu PTS(27).

Ao relacionar-se com o usuário de drogas, os profissionais podem compreender a relação que o usuário estabelece com a substância psicoativa que ele utiliza e, desta forma, esclarecer o objetivo deste em ter procurado um serviço especializado em saúde mental para tratamento de álcool e outras drogas.

\section{Conclusão}

O propósito desta investigação foi atingido, pois foi possível conhecer a percepção dos trabalhadores sobre a atuação do redutor de danos. Os achados deste estudo demonstraram que a RD ocupa um papel importante no âmbito da Reforma Psiquiátrica Brasileira e das políticas de atenção em saúde, pois surge com forma de enfrentamento das dificuldades de acesso ao cuidado em saúde de qualidade, considerando a singularidade de cada caso e garantindo os direitos fundamentais do cidadão.

Conclui-se que a percepção que os trabalhadores têm sobre a figura do profissional redutor de danos no CAPSad é que este tem, como capacidade, a criação de vínculos e a realização de um bom acolhimento e que pode auxiliar na desconstrução do estigma que o usuário de substâncias sofre perante a sociedade. Dessa forma, o processo de trabalho está em constante planejamento, reflexão e avaliação, sugerindo-se a construção de metas para o fortalecimento de sua atuação.

Compreende-se, portanto, a necessidade de estudos mais aprofundados que, além de evidenciar percepções de trabalhadores sobre a atuação da RD, possam demonstrar, de forma mais direta, as dificuldades específicas a fim de criar subsídios para a criação de ações, políticas e programas que possam fortalecer e apoiar o trabalho do redutor de danos. Um limite deste estudo foi sua realização a partir de um único CAPSad, o que implica a impossibilidade de conhecer diferentes percepções. 


\section{Referências}

1. Machado AR, Santos DC, Santos MP, Nogueira RC. Políticas públicas para uso prejudicial de álcool e outras drogas: avanços e retrocessos. In: Machado AR, Santos DC, Santos MP, Nogueira RC. Políticas públicas para uso prejudicial de álcool e outras drogas: avanços e retrocessos. Belo Horizonte: ESP-MG; 2018. p. 37-43.

2. Oliveira LG, Nappo SA. Caracterização da cultura de crack na cidade de São Paulo: padrão de uso controlado. Rev Saúde Pública. [Internet]. 2008;42(4):664-71. [Acesso 7 out 2019]. Disponível em: http://www. scielo.ebr/scielo.php?script=sci_arttext\&pid=S0034$89102008000400012 \& \operatorname{lng}=e n$. doi: 10.1590/ S0034-89102008005000039.

3. Tisott ZL, Hildebrandt LM, Leite MT, Martins RV, Cosentino SF. Álcool e outras drogas e a implantação da política de redução de danos no Brasil: revisão narrativa. Rev Atenção Saúde. 2015;13(43):79-89. doi: https://doi. org/10.13037/rbcs.vol13n43.2730

4. Souza, TPA. Norma da abstinência e o dispositivo "drogas": direitos universais em territórios marginais de produção de saúde (perspectivas da redução de danos). Campinas: Universidade Estadual de Campinas; 2013. Tese [Doutorado]. [Internet]. [Acesso 6 nov 2019]. Disponível em: http://www.bibliotecadigital.unicamp. br/document $/$ ?code $=000908456$

5. Almeida AS, Adamy PE, Siqueira E, Soares J, Cabral KV, Charao RB, et al. Percursos da Redução de Danos no Rio Grande do Sul. In: Fagundes S, Amorim A, Righi Heinzelmann R, organizadores. Atenção básica em produção: tessituras do apoio na gestão estadual do SUS. Porto Alegre: Rede UNIDA; 2014. p. 201-15. Disponivel em: https://www.lume.ufrgs.br/bitstream/ handle/10183/108866/000949575.pdf? sequence $=1$

6. Souza Satila EF, Mesquita CFB, Sousa FSP. Abordagem na rua às pessoas usuárias de substâncias psicoativas: um relato de experiência. Saúde Debate. [Internet]. 2017 mar [Acesso 8 out 2019]; 41(112):331-9. Disponível em: http://www.scielo.br/scielo.php?script $=$ sci_ arttext\&pid=S0103-11042017000100331\&Ing=en. doi: http://dx.doi.org/10.1590/0103-1104201711226.

7. Costa BA, Telles TCB. O processo de escuta na redução de da nos: contribuições de Rogers e Kierkegaard. Rev Abordagem Gestalt. [Internet]. 2017;23(1):74-83. [Acesso 8 out 2019]. Disponível em <http://pepsic.bvsalud.org/scielo.php?script=sci_ arttext\&pid=S1809-68672017000100009\&Ing=pt\&nrm $=$ iso $>$.

8. Wandekoken, KD, Siqueira MM de. Aplicação do Processo de Enfermagem a usuário de crack fundamentado no modelo de Betty Neuman. Rev Bras Enferm. 2014;67(1):62-70. doi: http://dx.doi. org/10.5935/0034-7167.20140008.
9. Tisott, ZL, Terra MG, Hildebrandt LM, Soccol KL, Souto VT.. Motivos da ação do redutor de danos junto ao usuário de drogas: um estudo fenomenológico. Rev Gaúcha Enferm. 2019; 40: e20180062. doi: http://dx.doi. org/10.1590/1983-1447.2019.20180062.

10. Nardi HC, Rigoni RQ. Mapeando programas de redução de danos da Região Metropolitana de Porto Alegre, Rio Grande do Sul, Brasil. Cad Saúde Pública 2009; 25(2):382-92. doi: http://dx.doi.org/10.1590/ S0102-311X2009000200017.

11. Silveira RM da, D'Tôlis POAO. Impactos da Ação de Agentes Redutores de Danos segundo Profissionais da Rede SUS. Rev Abordagem Gestáltica - Phenomenological Studies. [Internet]. 2016 [Acesso 12 jun 2020];22(1):7988. Disponivel em: http://pepsic.bvsalud.org/pdf/rag/ v22n1/v22n1a10.pdf

12. Decreto No 9.761, de 11 de abril de 2019 (BR). Aprova a Política Nacional sobre Drogas. Diário Oficial da União: seção 1-Extra. [Internet]. Brasília, DF, Edição: 70-A, n. 8, p. 7. [Acesso 30 nov 2019] Disponível em: http://www. planalto.gov.br/ccivil_03/_ato2019-2022/2019/decreto/ D9761.htm.

13. Minayo MCS. O Desafio da Pesquisa Social. In: Minayo MCS. Pesquisa social: teoria, método e criatividade. 30 ed. Petrópolis: Vozes; 2011. p. 9-29.

14. Polit DF, Beck CT. Fundamentos de pesquisa em enfermagem: avaliação de evidências para a prática da enfermagem. 7. ed. Porto Alegre: Artmed; 2011.

15. Munaretto LF, Corrêa HL, Cunha JAC. Um estudo sobre as características do método delphi e de grupo focal, como técnicas na obtenção de dados em pesquisas exploratórias. Rev Adm UFSM. (Santa Maria) 2013;6(1):924. doi: 10.5902/198346596243

16. Guba EG, Lincoln YS. Avaliação de Quarta Geração. Campinas: Editora da Unicamp; 2011. 318 p.

17. Ayres JRCM. Cuidado: trabalho e interação nas práticas de saúde. Rio de Janeiro: CEPESC - IMS/UERJ ABRASCO; 2011. 284 p.

18. Borges, LR. Sobre autonomias dirigidas e vestígios do passado: repercussões da gestão autônoma de medicamentos nas narrativas de trabalhadores da atenção básica. Dissertaçãso [mestrado]. Campinas: Universidade Estadual de Campinas; 2014. Disponível em: http:// repositorio.unicamp.br/bitstream/REPOSIP/313045/1/ Borges_LuanaRibeiro_M.pdf

19. Machado LV, Boarini ML. Políticas sobre drogas no Brasil: a estratégia de redução de danos. Psicol Ciênc Profissão. 2013;33(3):580-95. doi: http://dx.doi. org/10.1590/S1414-98932013000300006.

20. Petuco DRS, Medeiros RG. Saúde Mental, Álcool e outras Drogas. Contribuição à IV Conferência Nacional de Saúde Mental - Intersetorial. [Internet]. 2010. [Acesso 13 nov 2019]. Disponível em: http://www. redehumanizasus.net/9808-saude-mentalalcool- e-outras- 
drogas-contribuicao-a-iv-conferencia-nacional-de-saudementalintersetorial.

21. Carvalho B, Dimenstein M. Análise do discurso sobre redução de danos num CAPSad III e em uma comunidade terapêutica. Temas Psicol. [Internet]. 2017 [Acesso 6 nov 2019], 25(2):647-60. Disponível em: http://pepsic. bvsalud.org/scielo.php?script=sci_arttext\&pid=S1413389X2017000200013\&lng=pt. doi: http://dx.doi. org/10.9788/TP2017.2-13.

22. Souza SL, Melo LG. Acolhimento aos usuários de crack de um Centro de Atenção Psicossocial: os sentidos atribuídos pelos trabalhadores. SMAD, Rev Eletrônica Saúde Mental Álcool Drog. (Ed. port.) 2015;11(4):181-9. doi: 10.11606/issn.1806-6976.v11i4p181-189.

23. Silva AB, Pinho LB, Olschowsky A, Siniak DS, Nunes CK. O cuidado ao usuário de crack: estratégias e práticas de trabalho no território. Rev Gaúcha Enferm. [Internet]. 2016 [Acesso 13 jun 2020]; 37(spec):e68447. Disponível em: http://www.scielo.br/scielo.php?script =sci_ arttext\&pid=S1983-14472016000500404\&Ing=en.

24. Petuco DRS. Redução de danos: das técnicas à ética do cuidado. In: Ramminger T, Silva M, organizadores. Mais substâncias para o trabalho em saúde com usuários de drogas. Porto Alegre: Rede Unida; 2014. p. 133-48. 25. Scheffer AM, Antunes N, Büchele F. Redução de danos como estratégia de trabalho junto aos usuários de drogas nas unidades locais de saúde do Interfaces Científicas - Saúde e Ambiente, Município de Florianópolis. Cad Bras Saúde Mental. [Internet]. 2011. [Acesso 15 out 2019];3(7):73-92. Disponível em: https://periodicos.ufsc. br/index.php/cbsm/article/view/68629.

26. Anjos FNC dos, Souza AMP de. A percepção sobre o trabalho em equipe multiprofissional dos trabalhadores de um Centro de Atenção Psicossocial em Salvador, Bahia, Brasil. Interface. (Botucatu) 2017;21(60):63-76. doi: http://dx.doi.org/10.1590/1807-57622015.0428.

27. Ministério da Saúde (BR). Secretaria de Atenção à Saúde. Departamento de Atenção Básica. Departamento de Ações Programáticas Estratégicas. Brasília: Ministério da Saúde; 2013. 176 p.

\section{Contribuição dos Autores}

Concepção e planejamento do estudo: Diego Fernandes Leal, Vanessa Alvez Mora da Silva e Luana Ribeiro Borges. Obtenção dos dados: Diego Fernandes Leal, Vanessa Alvez Mora da Silva e Luana Ribeiro Borges. Análise e interpretação dos dados: Diego Fernandes Leal, Vanessa Alvez Mora da Silva e Luana Ribeiro Borges. Análise estatística: Diego Fernandes Leal. Redação do manuscrito: Diego Fernandes Leal e Vanessa Alvez Mora da Silva. Revisão crítica do manuscrito: Diego Fernandes Leal, Vanessa Alvez Mora da Silva, Luana Ribeiro Borges, Sandra Beatris Diniz Ebling e Aline Ost dos Santos.

Todos os autores aprovaram a versão final do texto. Conflito de interesse: os autores declararam que não há conflito de interesse. 